\title{
Empirical sea ice thickness retrieval during the freeze-up period from SMOS high incident angle observations
}

\author{
M. Huntemann ${ }^{1}$, G. Heygster ${ }^{1}$, L. Kaleschke ${ }^{2}$, T. Krumpen ${ }^{3}$, M. Mäkynen ${ }^{4}$, and M. Drusch ${ }^{5}$ \\ ${ }^{1}$ Institute of Environmental Physics, University of Bremen, Bremen, Germany \\ ${ }^{2}$ Institute of Oceanography, University of Hamburg, Hamburg, Germany \\ ${ }^{3}$ Alfred Wegener Institute, Bremerhaven, Germany \\ ${ }^{4}$ Finnish Meteorological Institute, Helsinki, Finland \\ ${ }^{5}$ ESTEC, ESA, Noordwijk, Netherlands \\ Correspondence to: M. Huntemann (marcus.huntemann@uni-bremen.de)
}

Received: 30 July 2013 - Published in The Cryosphere Discuss.: 30 August 2013

Revised: 20 January 2014 - Accepted: 10 February 2014 - Published: 18 March 2014

\begin{abstract}
Sea ice thickness information is important for sea ice modelling and ship operations. Here a method to detect the thickness of sea ice up to $50 \mathrm{~cm}$ during the freeze-up season based on high incidence angle observations of the Soil Moisture and Ocean Salinity (SMOS) satellite working at $1.4 \mathrm{GHz}$ is suggested. By comparison of thermodynamic ice growth data with SMOS brightness temperatures, a high correlation to intensity and an anticorrelation to the difference between vertically and horizontally polarised brightness temperatures at incidence angles between 40 and $50^{\circ}$ are found and used to develop an empirical retrieval algorithm sensitive to thin sea ice up to $50 \mathrm{~cm}$ thickness. The algorithm shows high correlation with ice thickness data from airborne measurements and reasonable ice thickness patterns for the Arctic freeze-up period.
\end{abstract}

\section{Introduction}

Sea ice is an essential climate component and observations of its formation, evolution, and decay are important for understanding and predicting climate change. Sea ice coverage has been observed since 1972 using several microwave radiometers, namely the Electrically Scanning Microwave Radiometer (ESMR) (1972-1977), Scanning Multi-channel Microwave Radiometer (SMMR) (1978-1987), Special Sensor Microwave Imager (SSM/I) (1987-present), Advanced Microwave Scanning Radiometer - Earth Observing System (EOS) (AMSRE) (2002-2012) and AMSR2 (2012-present).
The sensitivity of the microwave emission of sea ice has been narrowed down to a few essential microphysical properties like sea ice thickness, salinity, temperature and snow grain size (Tonboe et al., 2011; Fuhrhop et al., 1998). Since 2009 the ESA (European Space Agency) Soil Moisture and Ocean Salinity (SMOS) mission, has been observing the Earth at 1.4 GHz (L-band), from a sun synchronous dusk-dawn orbit (Kerr et al., 2001). At this microwave frequency, the penetration depth into sea ice is about $50 \mathrm{~cm}$ and even more into ice of less saline waters like the Baltic Sea (Kaleschke et al., 2010).

Figure 1 (left) illustrates the basic situation: the brightness temperature of open water at nadir is around $100 \mathrm{~K}$. For vertical polarisation, it increases with incidence angle up to $180 \mathrm{~K}$ at $65^{\circ}$, and for horizontal polarisation it decreases down to about $60 \mathrm{~K}$. At all incidence angles, the signal of sea ice is clearly higher. The vertically polarised emission increases from $230 \mathrm{~K}$ at nadir to $260 \mathrm{~K}$ at $65^{\circ}$, and the horizontally polarised emission decreasing down to $215 \mathrm{~K}$.

Because of the high penetration depth at $\mathrm{L}$ band and the high brightness temperature contrast of over $100 \mathrm{~K}$ between ice and open water, increasing sea ice thickness is reflected in the L-band emission. Therefore it appears attractive to assess the potential of retrieving sea ice thickness (SIT) with SMOS. Kaleschke et al. $(2010,2012)$ first showed that for observations of up to $40^{\circ}$ incident angle, the intensity can be used to obtain information on the sea ice thickness. 

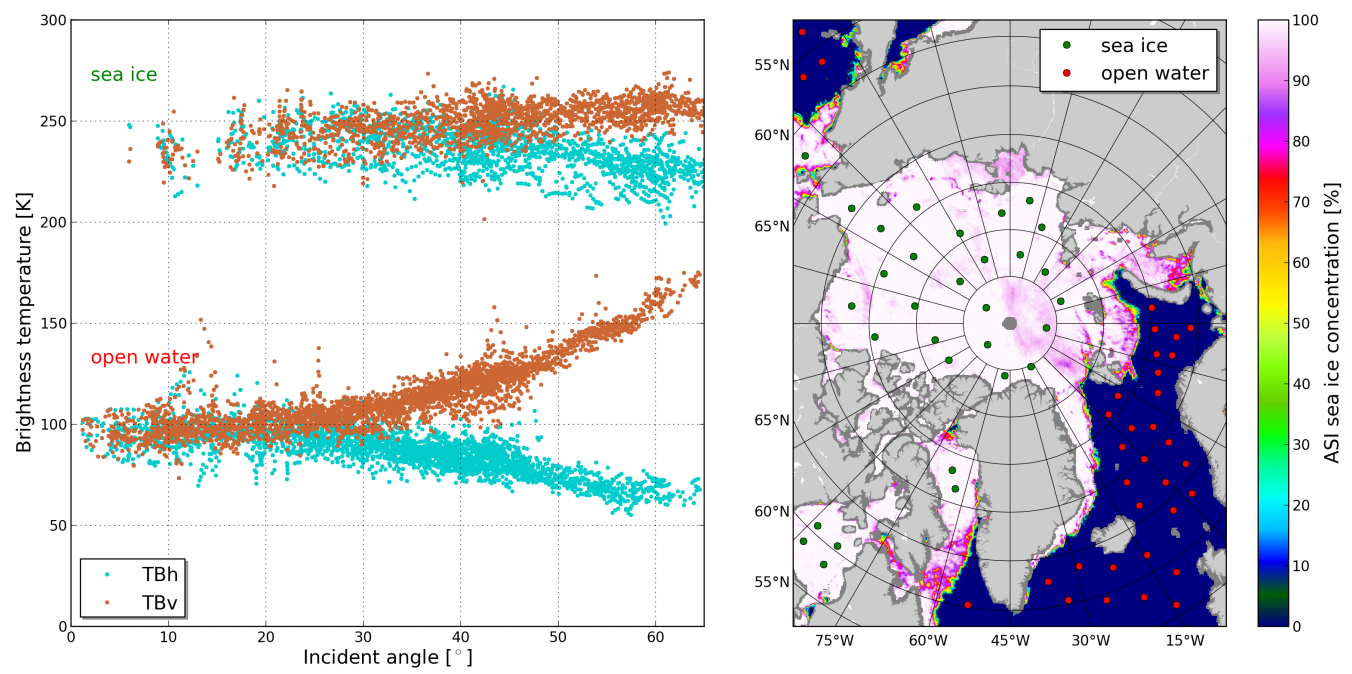

Fig. 1. Testing large area of brightness temperatures throughout the whole Arctic area from 20 April 2012. Right: ice concentration from SSM/I and test areas for sea ice (green bullets) and open water (red bullets). Left: the corresponding brightness temperature dependence on the incident angle.

In this paper we use the brightness temperatures at higher incidence angles between 40 and $50^{\circ}$ which allows us to exploit, in addition to the intensity the polarisation difference, the difference between the intensities observed at vertical and horizontal polarisation. As a consequence, this method will employ input data independent of those used by Kaleschke et al. (2012).

The results are compared with an ice thickness retrieval based on the Moderate-resolution Imaging Spectroradiometer (MODIS) (Sect. 4.1) and ice thicknesses obtained from a helicopter using the so-called EM-bird instrument (Sect. 4.2). In addition, daily differences of the suggested SMOS retrieval applied to the whole Arctic are checked for consistency (Sect. 4.3).

\section{SMOS data source and processing}

The instrument Microwave Imaging Radiometer with Aperture Synthesis (MIRAS) onboard of the SMOS satellite provides data since 2010 (Mecklenburg et al., 2012). Each of its 69 receivers, organised along the shape of a three-leg star, measures radiances from which brightness temperatures are determined. The unit of data processed in one aperture synthesis step is called a snapshot (Fig. 2), a set of about $100 \times 100$ brightness temperatures generated from the initial observations by essentially correlating the signals from the 69 receivers amongst each other and applying a Fourier-like back transform (Corbella et al., 2004). Each 1.2 s, one snapshot is taken.

We are using two types of input data, SMOS Level 1C data and Binary Universal Form for the Representation of meteorological data (BUFR). In both input formats the data is provided gridded in the icosahedron Snyder equal area (ISEA)

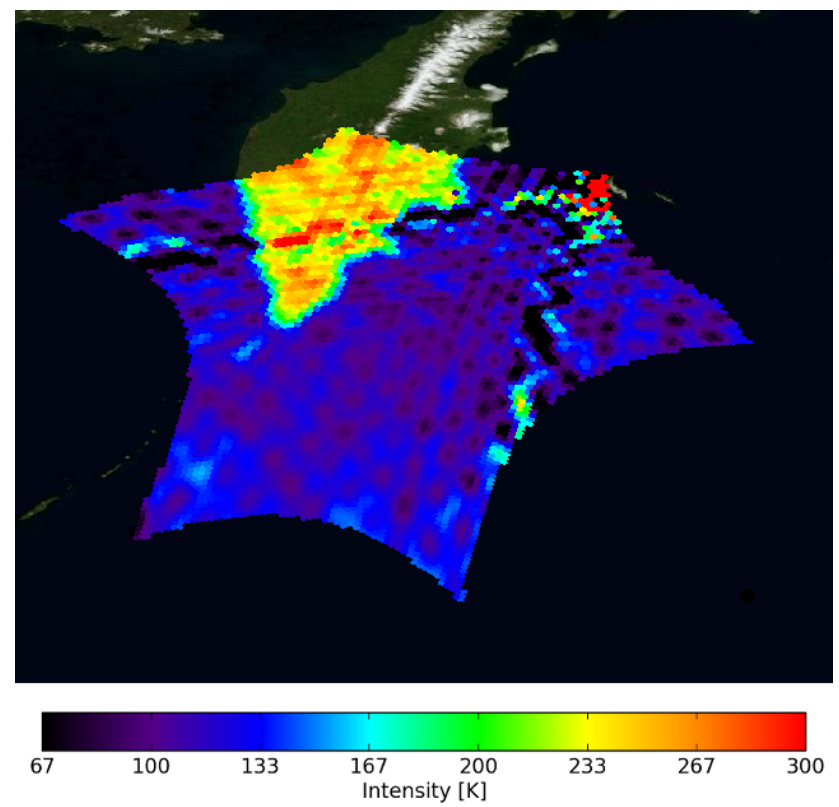

Fig. 2. A SMOS snapshot of Kamchatka and the Sea of Okhotsk as taken by MIRAS. The red area in the upper right of the snapshot represents high brightness temperatures due to RFI. In addition it produces ringing structures because of the inverse Fourier transform like reconstruction of the image.

4H9 grid (Sahr et al., 2003), an equal area grid. The gridding introduces positional errors of no more than a few kilometres, which are not critical since the SMOS footprint is at nadir about $30 \mathrm{~km} \times 30 \mathrm{~km}$, increasing with incident angle up to $90 \mathrm{~km} \times 33 \mathrm{~km}$ at about $65^{\circ}$. In this paper we work with incidence angles of $40-50^{\circ}$ where the footprint is about 


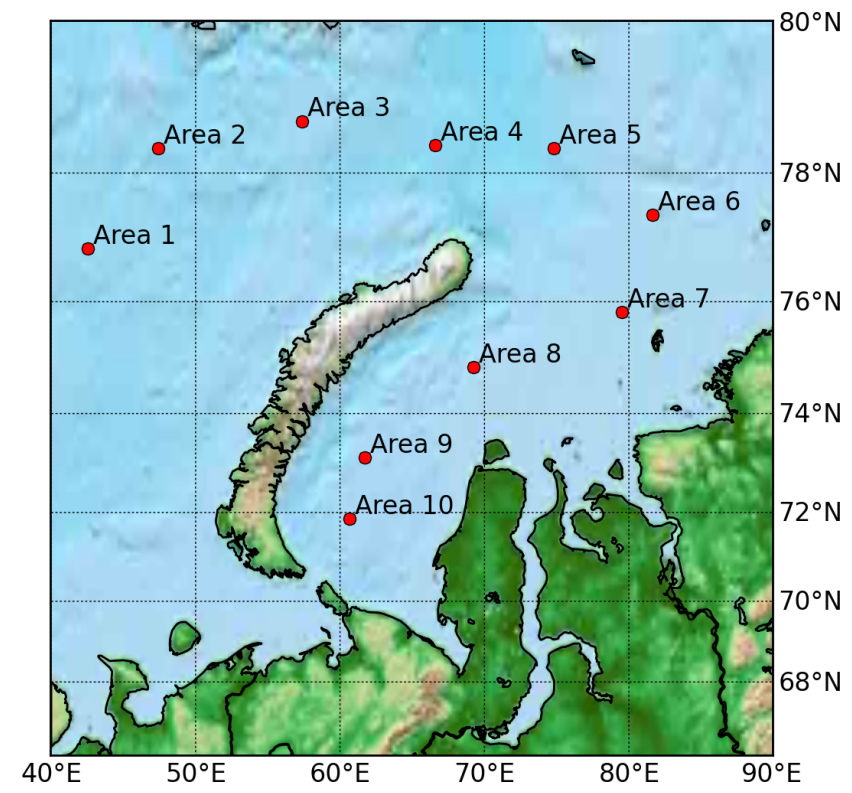

Fig. 3. Location of training areas.

$50 \mathrm{~km} \times 31 \mathrm{~km}$. As each footprint overlaps several grid points (Castro, 2008), the data of neighbouring grid points are correlated.

The L1C data cover the whole ISEA 4H9 discrete global grid (DGG), but are available with an about 24-48 h delay. As for operational sea ice services, a shorter delay is required, the BUFR data, offering SMOS data with only a 3$4 \mathrm{~h}$ delay, are used. In order to reduce the data volume, over the ocean in the BUFR data only every other DGG cell is represented.

Even though the frequency band near $1.4 \mathrm{GHz}$ is not allowed for communication, RFIs (radio frequency interferences) have been strong during the early phase of the SMOS mission. They have been reduced since then, but not completely eliminated (Camps et al., 2010; Oliva et al., 2012).

The RFI-influenced data shows mostly higher brightness temperatures $\left(T_{\mathrm{b}}\right)$ than occur in nature. All surface emissions of more than $T_{\mathrm{b}}=300 \mathrm{~K}$ are unrealistic because they would require an emissivity larger than unity and are taken as RFI in our processing. Due to the Fourier-transform-like reconstruction of the snapshots, a strong RFI from a single source on Earth's surface may extend over the whole snapshot, albeit at lower values. In order to also discard lower RFI influences, in our processing the whole snapshot is discarded if at least one pixel shows a brightness temperature larger than $300 \mathrm{~K}$. An example of RFI can be seen in the snapshot in Fig. 2.

Since May 2010, SMOS has been operating in full polarisation mode, i.e. measuring all four Stokes components. However, these are delivered in the L1C and BUFR data sets with respect to the instrument reference plane $(X, Y)$ and need to be converted to Earth's surface plane $(V, H)$ by the transformation

$$
\begin{aligned}
& {\left[\begin{array}{l}
A_{1} \\
A_{2} \\
A_{3} \\
A_{4}
\end{array}\right]=} \\
& {\left[\begin{array}{cccc}
\cos ^{2}(\alpha) & \sin ^{2}(\alpha) & -\cos (\alpha) \sin (\alpha) & 0 \\
\sin ^{2}(\alpha) & \cos ^{2}(\alpha) & \cos (\alpha) \sin (\alpha) & 0 \\
\sin (2 \alpha) & -\sin (2 \alpha) & \cos (2 \alpha) & 0 \\
0 & 0 & 0 & 1
\end{array}\right]\left[\begin{array}{l}
T B_{H} \\
T B_{V} \\
T B_{3} \\
T B_{4}
\end{array}\right],}
\end{aligned}
$$

with $A_{1}=\Re\left(T B_{X X}\right), A_{2}=\Re\left(T B_{Y Y}\right), A_{3}=$ $2 \Im\left(T B_{X Y}\right), A_{4}=-2 \Im\left(T B_{X Y}\right)$ and $\alpha=\alpha_{r}+\omega_{F_{\alpha}}$, where $\alpha_{r}$ and $\omega_{F_{\alpha}}$ are geometric rotation angle and Faraday rotation angle, respectively (Zine et al., 2008), which are supplied in the SMOS L1C and BUFR data. $\Re(\ldots)$ and $\Im(\ldots)$ are the real and imaginary parts, respectively.

The transformation needs for each observation in the $(V$, $H$ ) frame brightness temperatures at three polarisations: $X X$, $Y Y$ and $X Y$. However, only one (either $X X$ or $Y Y$ ) or two of them (either $(X X, X Y)$ or $(Y Y, X Y))$ are measured within one snapshot so that either one or two missing values need to be interpolated.

We use observations from neighbouring, overlapping snapshots acquired within $2.5 \mathrm{~s}$ before or after the time of interest (SMOS takes snapshots every $1.2 \mathrm{~s}$ ). Within $2.5 \mathrm{~s}$ the atmosphere and surface conditions should change only little. If no suitable values for interpolation can be found, this observation is discarded from the transformation and further data analysis. As an additional condition, the incidence angle may only vary less than $0.5^{\circ}$, which ensures the accuracy of the interpolation since the polarised brightness temperatures vary quite strongly at $40-50^{\circ}$ incident angles (Fig. 1).

\section{Sea ice thickness retrieval method}

The first step to develop a fully empirical retrieval was to get training data and analyse it for consistency. Since SIT of thin ice during the freeze-up period is hard to observe in situ (one cannot stand or walk on it), we had to rely on other, model based sources as a reference for comparison.

- The HIGHTSI (Launiainen and Cheng, 1998), a regional, thermodynamic one-dimensional sea ice growth model driven by the High Resolution Limited Area Model (HIRLAM), (Källen, 1996; Unden et al., 2002), a short-range weather forecasting system intended to use for limited areas developed by eleven European countries (www.hirlam.org). HIGHTSI was employed to model the freeze-up period 2010 in the Barents Sea and Kara Sea.

- Towards an Operational Prediction system for the North Atlantic European coastal Zones (TOPAZ) (Sakov et al., 2012), a coupled global ocean-sea ice 


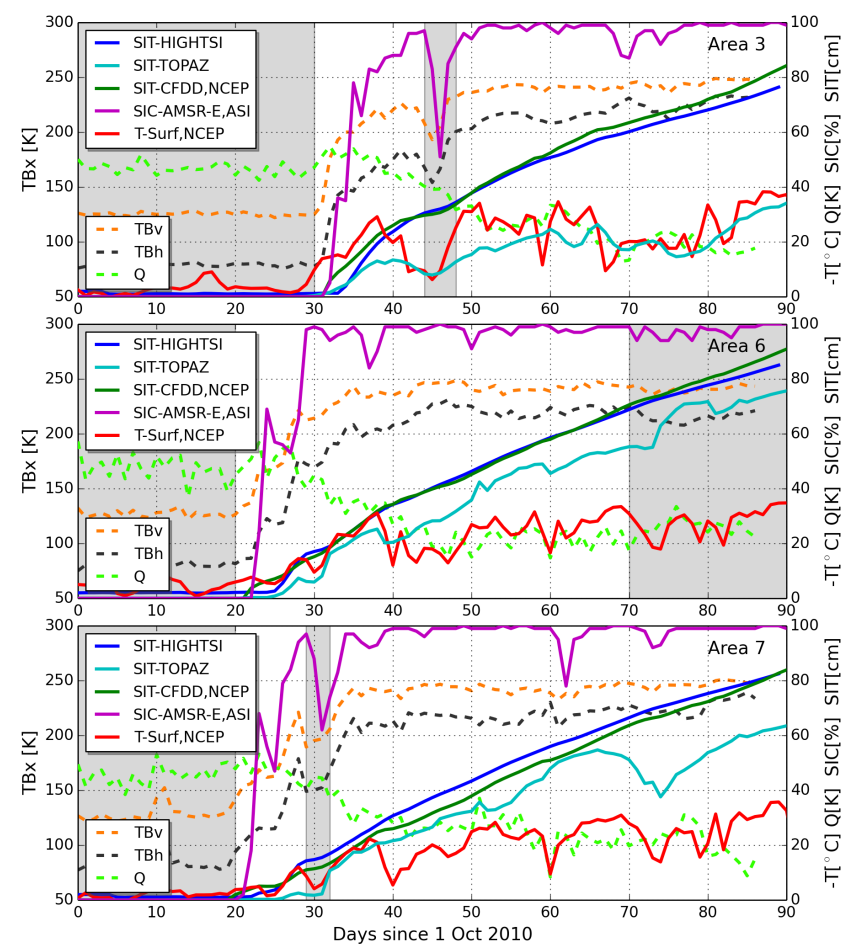

Fig. 4. SIT of training areas 3, 6 and 7 (for location see Fig. 3) from TOPAZ, HIGHTSI and NCEP, air temperature from NCEP, SIC from ASI (AMSRE) and SMOS brightness temperatures. Left $Y$ axis for $T_{\mathrm{B}_{\mathrm{h}}}$ and $T_{\mathrm{B}_{\mathrm{v}}}$, right $Y$ axis for $Q$, all SITs, SIC and temperature; shaded areas are excluded for retrieval training.

data assimilation system which, among other, provides information on sea ice thickness and sea ice concentration. For our analysis we used data from the TOPAZ V3 model.

- National Centers for Environmental Prediction (NCEP) and National Center for Atmospheric Research (NCAR) produce analysis/reanalysis data out of observations and historic data, frequently used as reference for global climate variables and for initialising mesoscale atmospheric models. The spatial resolution is $2.5^{\circ}$ (Kalnay et al., 1996).

While TOPAZ and HIGHTSI contain the SIT directly, (NCEP) data can only be used to calculate the SIT using the air temperature as input for the empirical Cumulative Freezing Degree days (CFDD) model (Bilello, 1961; Weeks, 2010, p. 35-39):

$\operatorname{SIT}[\mathrm{cm}]=1.33 \cdot\left(\operatorname{CFDD}\left[{ }^{\circ} \mathrm{C}\right]\right)^{0.58}$,

where CFDD is the daily average temperature below the freezing point of sea water $\left(-1.8^{\circ} \mathrm{C}\right)$, integrated over the time period since the first sea ice has been formed at this point and in this ice season.
Because of the limited region covered by HIGHTSI, we chose ten grid cells in the Kara and Barents seas shown in Fig. 3, in the Arctic freeze-up period from 1 October to 26 December 2010.

In this region the sea ice drift is on average of the order of $8 \mathrm{~km} \mathrm{day}^{-1}$, according to the low resolution ice drift product of the Ocean and Sea Ice Satellite Application Facility (OSI-SAF) (Lavergne et al., 2010). This is about a half of the size of the $15 \mathrm{~km}$ grid cell used here (Sect. 2), so that the influence of sea ice drift from one day to the next may be neglected. Therefore, 1-D models like HIGHTSI or the CFDD can be applied without introducing too large errors from the 1-D assumption. The training areas are in a sufficient distance from each other so that the CFDD based SITs are not obtained from the same grid cell of the NCEP grid. Another advantage of these areas is their high ice concentration after freeze-up according to AMSRE and SSM/I sea ice concentrations as retrieved with the ASI algorithm (Spreen et al., 2008) available at http://www.iup.uni-bremen.de:8084/amsr.

For all ten areas in Fig. 3 the ice thicknesses from HIGHTSI, TOPAZ and from the CFDDs based on NCEP air temperatures were analysed as a function of SMOS brightness temperatures from in the incident angle range from 40 to $50^{\circ}$ (not shown here). Here we discuss the time series for areas 3 , 6 and 7 shown in Fig. 4 together with NCEP air temperatures and the sea ice concentration (SIC) from the ASI algorithm using AMSRE (Spreen et al., 2008). Figure 4 shows additionally the SMOS horizontal and vertical brightness temperatures ( $T_{\mathrm{B}_{\mathrm{h}}}$ and $T_{\mathrm{B}_{\mathrm{v}}}$, respectively) and the polarisation difference $Q=T_{\mathrm{B}_{\mathrm{h}}}-T_{\mathrm{B}_{\mathrm{v}}}$.

The only ice thickness which can decrease during the freeze-up period is the one based on the TOPAZ model since it includes drift and melt. HIGHTSI also models ice and snow melting if the temperature goes above zero. The main difference to TOPAZ is that HIGHTSI does not include ice growth due to drift and deformation. In general, HIGHTSI predicts thickness of level ice with $100 \%$ SIC, i.e. undeformed ice. Naturally CFDD does not include ice melting.

Figure 4 reveals a high correlation of the SMOS brightness temperatures $T_{\mathrm{B}_{\mathrm{h}}}$ and $T_{\mathrm{B}_{\mathrm{v}}}$ with the SIT from the models up to about $30-40 \mathrm{~cm}$ thickness. Moreover $T_{\mathrm{B}_{\mathrm{h}}}$ and $T_{\mathrm{B}_{\mathrm{v}}}$ are getting closer to each other with increasing ice thickness as can be seen from the brightness temperature difference $Q$. The brightness temperatures are not only influenced by the SIT but also by the SIC. In the current SIT retrieval approach, the SIC is assumed to be equal to $100 \%$. However if we restrict the SIC in the training data set to $100 \%$ SIC, we risk to miss the formation of very thin sea ice because SIC retrievals from current passive microwave algorithms yield ice concentrations below $100 \%$ in case of a thin ice cover (Kwok et al., 2007; Kern et al., 2007). In order not to miss these initial ice thicknesses, we include observations with the initial increase of ice concentration from 0 to $100 \%$ (days 20-29 in Fig. 4, bottom) into the training data set while later drops in SIC, possibly ice breakups, are excluded (days 30-32 in Fig. 4, 


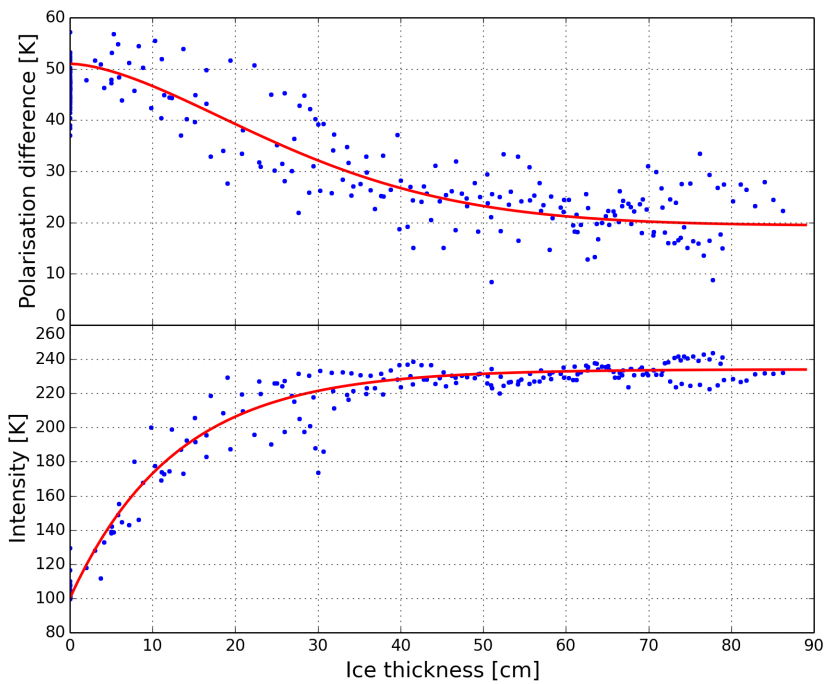

Fig. 5. Dependence of polarisation difference (top) and intensity (bottom) to ice thicknesses obtained from CFDD from NCEP/NCAR surface air temperature data. Red line shows a fit of an empirical function of polarisation difference and intensity to ice thickness.

bottom). Excluded areas are shaded grey in Fig. 4. Similar investigations have been carried out for all 10 regions in Fig. 3 (Heygster et al., 2012).

In several of the regions, SIT did not increase monotonically as SIC decreased over longer periods or freeze-up was late in the investigation period. As a result, only areas 3, 6 and 7 show monotonic freeze-up periods sufficiently contiguous for our analysis (Fig. 4). As ice forms there is a high correlation of temperature to the brightness temperatures measured by SMOS. Since the temperature drives the CFDD based ice thickness model this correlation is expected. However, the air temperature does not seem to have a direct influence on the brightness temperature in case of thicker ice. In area 3 (day 67), area 6 (day 37) and area 7 (days 60 and 73) an increase in temperature is connected with a drop of SIC to about $90 \%$. Overall the temperatures are relatively stable around $-20{ }^{\circ} \mathrm{C}$ without any melt events in these three regions. TOPAZ shows considerably lower SIT in area 3 than the other non-dynamic models. However, we tend to trust the HIGHTSI and NCEP based thicknesses as the temperature is almost all the time below $-20^{\circ} \mathrm{C}$ where a steady ice thickness growth is expected. Between the $I$ and $Q$ parameters and SIT obtained from the models for each of the different training areas the following functions are fitted:

$$
\begin{aligned}
I_{a b c}(x) & =a-(a-b) \cdot \exp (-x / c), \\
Q_{a b c d}(x) & =(a-b) \cdot \exp \left(-(x / c)^{d}\right)+b .
\end{aligned}
$$

Equation (3) is also used in Kaleschke et al. (2012) and is basically the Lambert-Beer law. Equation (4) was chosen empirically since it allows us to represent the shape of thickness dependence of the polarisation difference in an appropriate way.

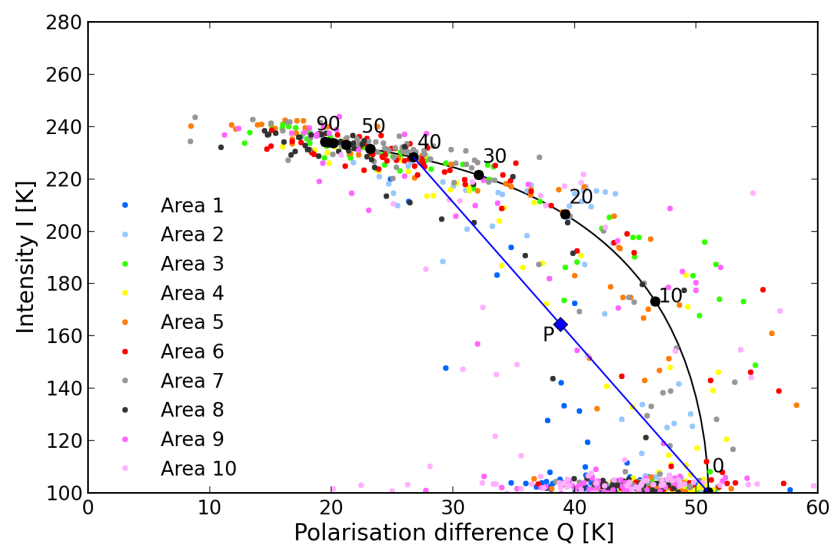

Fig. 6. Retrieval curve of SIT from $I$ and $Q$. Dot colours belong to different regions (see Fig. 3). Numbers at the curve mark the retrieved SIT in centimetre. Observation point $\mathrm{P}$ can be synthesised by observing thicknesses of 0 and $40 \mathrm{~cm}$ (blue line) in one footprint.

Table 1. Parameters for fit function in Eqs. (3) and (4).

\begin{tabular}{lllll}
\hline Parameter & $a[\mathrm{~K}]$ & $b[\mathrm{~K}]$ & $c[\mathrm{~cm}]$ & $d$ \\
\hline$I_{a b c}$ & 234.1 & 100.2 & 12.7 & - \\
$Q_{a b c d}$ & 44.8 & 19.4 & 24.1 & 2.1 \\
\hline
\end{tabular}

Figure 5 shows the relation between the SIT and the polarisation difference $Q$ and intensity $I$, respectively, in our training data set. The sensitivity of $I$ to sea ice thickness decreases from $30 \mathrm{~cm}$ onwards, whereas $Q$ is sensitive up to about $50 \mathrm{~cm}$, considering their range of variation. However, it is important to mention here that the relative error of the brightness temperature difference is higher than it is with the intensity.

For training, only the CFDD derived SIT from NCEP data is used, so that the HIRLAM based MODIS retrieval may serve in the next section as independent comparison data. Since HIGHTSI is also driven by HIRLAM, HIGHTSI data is not used for training. Table 1 shows the optimal parameters for Eq. (3) which best represent the training data set as seen in Fig. 5.

Figure 6 shows the two functions as a parameterised curve in the $(Q, I)$ plane. The colour of the points indicates the different regions (Fig. 3). The curved black line represents the SIT retrieved for a given pair $(Q, I)$. To find the SIT for given $I$ and $Q$, the minimum Euclidean distance to the retrieval curve is determined. Figure 6 shows that changes in $Q$ only influence the retrieved SIT at higher intensities, i.e. SIT higher than $30 \mathrm{~cm}$ as expected from Fig. 5 .

At higher SIT the returned values are sensitive even to small changes of the observed $I$ and $Q$. The uncertainty of the instrument is about $2-3 \mathrm{~K}$ for a single measurement (Brown et al., 2008). The error budget of daily averages within one grid cell is reduced by the averaging over the 

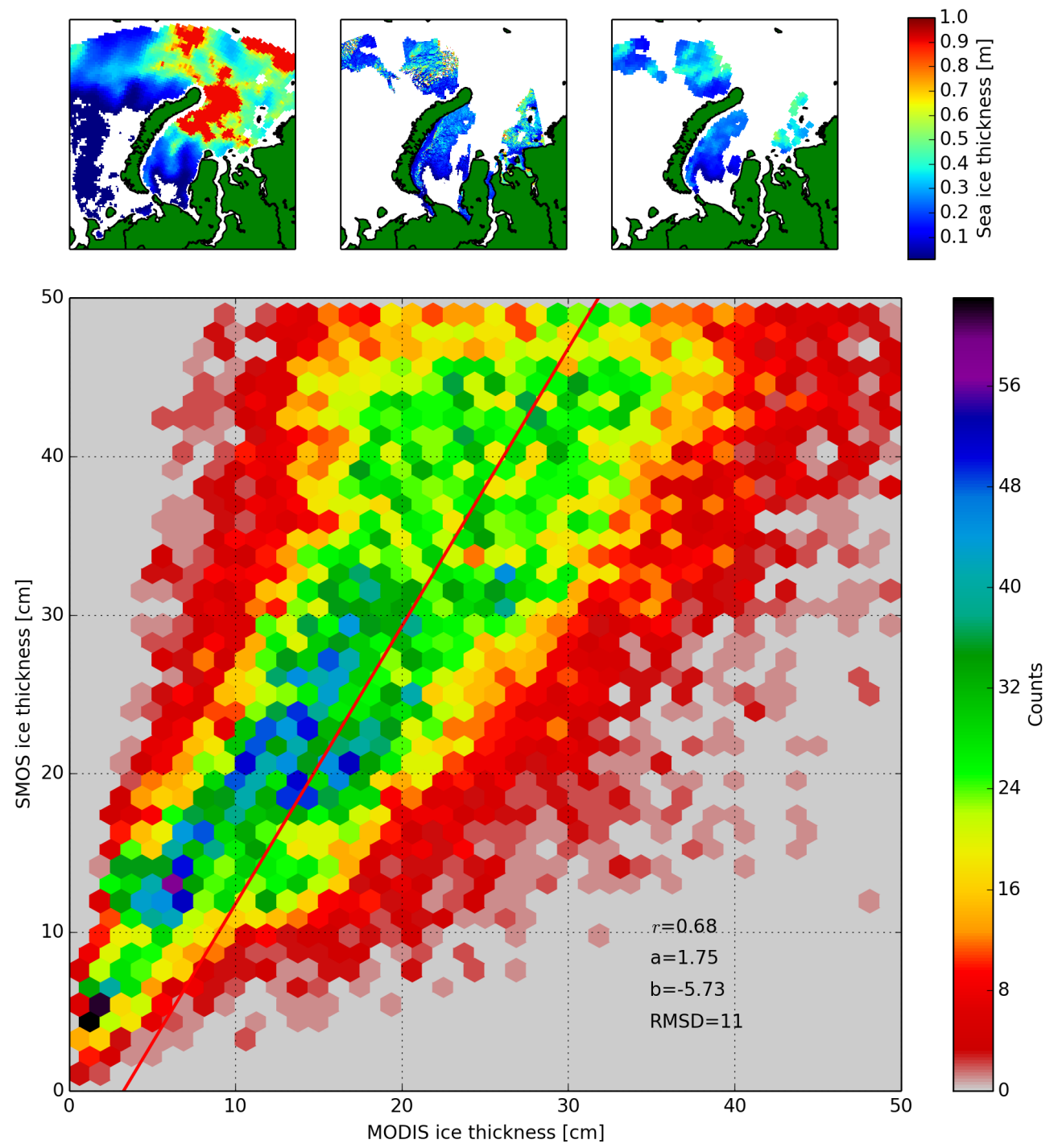

Fig. 7. Comparison between SMOS (top left) and MODIS (top centre) retrieved SIT for 4 December 2010 in the Kara Sea. The valid MODIS data after averaging to the SMOS footprint size (top right). The scatter plot of MODIS and SMOS for all MODIS data from 24 November 2010 to 14 April 2011 (71 scenes) (bottom). Regression line (red): $y=1.75 x-5.73$, RMSD $=11 \mathrm{~cm}$, correlation of $r=0.68$.

incidence angle range of $40-50^{\circ}$, but increased by the emissivity variations with incidence angle (Fig. 1, left). As the sensitivity of the retrieved SIT to both intensity and polarisation difference increases strongly with SIT (Figs. 5, 6), the retrieval is cut off at $50 \mathrm{~cm}$ SIT.

Higher retrieved values are marked by a flag for more than $50 \mathrm{~cm}$ but no distinct values are returned.

It should be mentioned that the retrieval in the present form assumes ice concentrations of $100 \%$. Introducing a second observation $Q$ in the retrieval would in principle allow us to determine simultaneously a second parameter, e.g. the ice concentration. An example observation, $P=(Q, I)$ (Fig. 6), could then be explained as a linear combination of open water (ice thickness $0 \mathrm{~cm}$ ) and $40 \mathrm{~cm}$ thick ice. However, attempts to establish such a two-parameter retrieval have turned out to be quite noisy (Heygster et al., 2012). Therefore, here we refrain from a two-parameter retrieval. The advantage of introducing a second parameter is rather a gain of sensitivity in the upper range of ice thicknesses.

\subsection{Error estimation}

For each $10 \mathrm{~cm}$ interval of the training NCEP CFDD SIT, the RMSD (root mean square deviation) to the SIT retrieved from SMOS is shown in Table 2. The uncertainty is about $30 \%$ of the retrieved value. The retrieval of very thin ice of $0-20 \mathrm{~cm}$ is quite accurate and stable. Higher retrieved SITs have a larger uncertainty and because of the restriction of the SIT retrieval to $50 \mathrm{~cm}$, it might yield larger than stated deviations close to the $50 \mathrm{~cm}$ border. The RMSD values in 

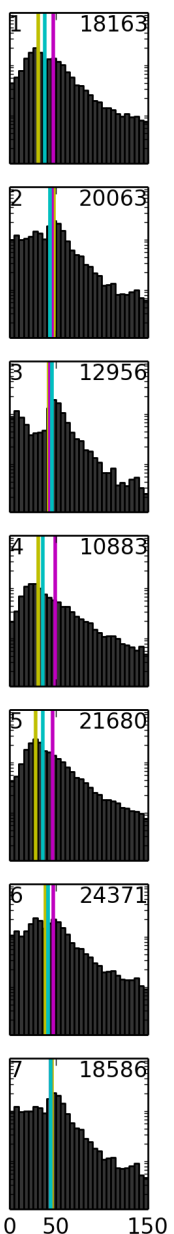
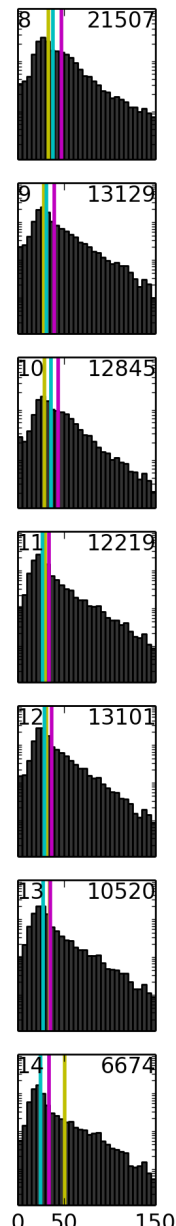

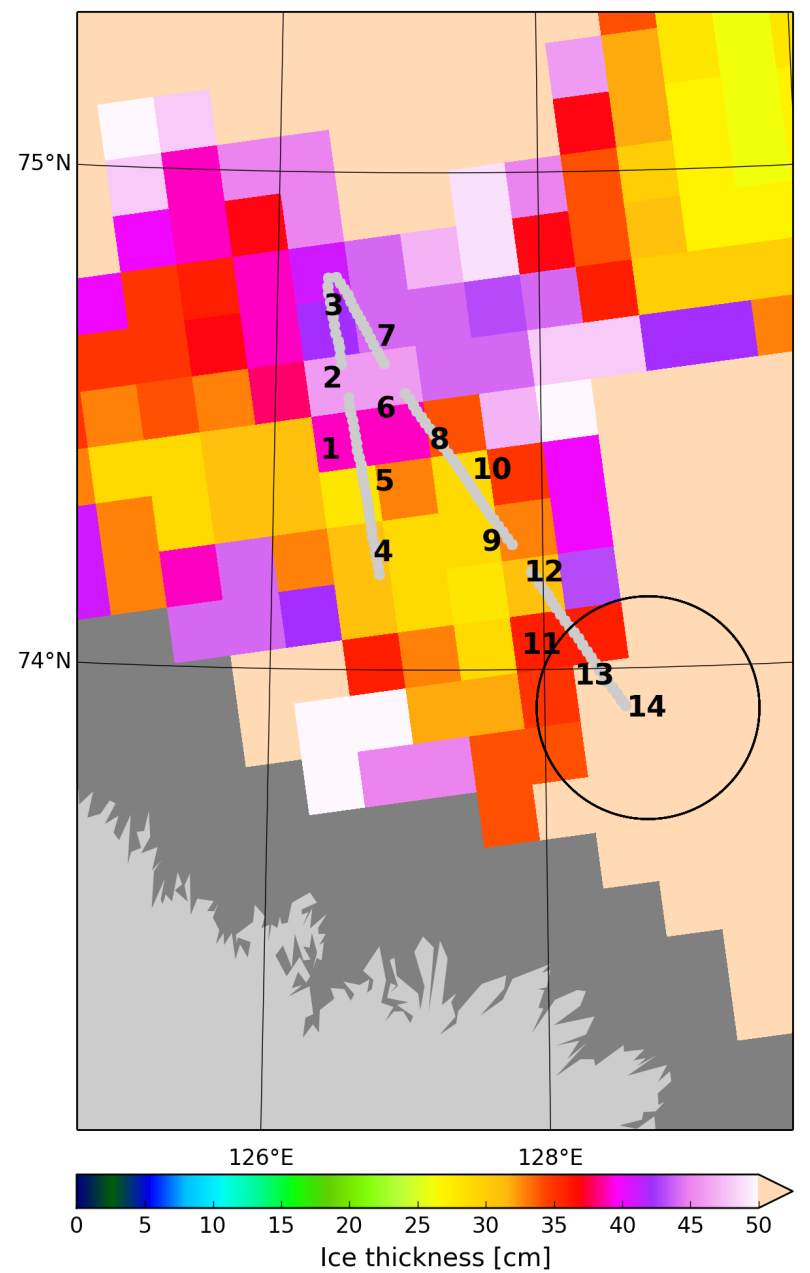

Fig. 8. Comparison of EM bird and SMOS SIT. (right) Location of EM bird flight of 20 April 2012 (grey track) over SMOS retrieved SIT in NSIDC $12.5 \mathrm{~km}$ grid (coloured background tiles). The numbers along the flight track indicate the native SMOS $15 \mathrm{~km}$ ISEA grid points. The large black circle illustrates the average size of a SMOS footprint. (left) Histograms of EM bird SIT retrievals within circular regions of SMOS footprint size centered around the same number (upper left of each histogram) in the right-hand image. The number of EM bird measurements for each histogram is shown in the upper right. The coloured vertical lines correspond to the mean (purple) and median (cyan) of the EM bird measurements while yellow lines indicate the retrieved SIT by SMOS.

Table 2 describe how well the retrieval curve represents the learning data set based on the NCEP CFDD data. It includes the uncertainties introduced by the NCEP and CFDD models and by sea ice drift. In the next chapter the retrieved SIT values will be compared to independent SIT values, making the error characterisation independent of the learning data set.

\section{Validation and comparison}

Since SIT is difficult to obtain in situ, we compare our retrieval to remote sensing data sets from MODIS and from helicopter flights carrying an EM bird instrument. In addition we check our retrieval for self consistency by comparing day-to-day changes of SIT.
Table 2. Retrieval characteristics from learning and independent validation data sets. $r$ correlation coefficient.

\begin{tabular}{|c|c|c|c|}
\hline Data set & $\begin{array}{r}\text { thickness range } \\
{[\mathrm{cm}]}\end{array}$ & $\begin{array}{r}\text { RMSD } \\
{[\mathrm{cm}]}\end{array}$ & $r$ \\
\hline \multirow[t]{6}{*}{ CFDD (learning) } & $0-10$ & 3 & \\
\hline & $10-20$ & 7 & \\
\hline & $20-30$ & 9 & \\
\hline & $30-40$ & 14 & \\
\hline & $40-50$ & 16 & \\
\hline & average $0-50$ & 10 & \\
\hline MODIS & $0-50$ & 11 & 0.68 \\
\hline EM bird & $0-50$ & 5 & 0.73 \\
\hline
\end{tabular}




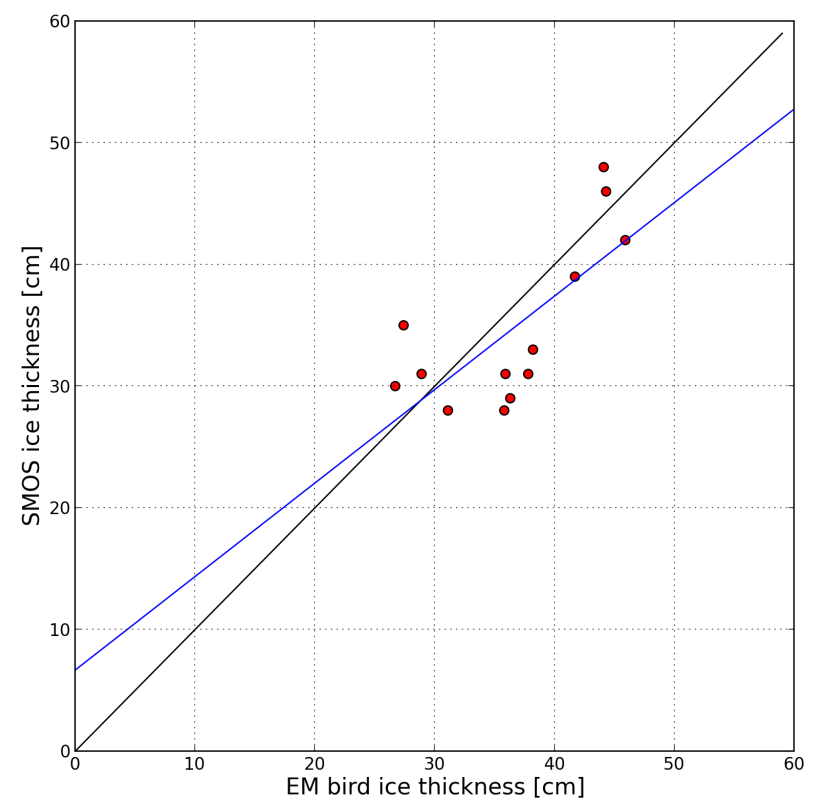

Fig. 9. Scatter plot of EM bird versus SMOS SIT retrieval. Blue: regression line. RMSD between data and regression line: $5 \mathrm{~cm}$, correlation of $r=0.73$.

\subsection{Using MODIS thermal imagery SIT retrieval}

MODIS based ice surface temperature together with HIRLAM atmospheric forcing data was used to estimate thin ice thickness over the Barents and Kara seas through the ice surface heat balance equation (Yu and Rothrock, 1996; Mäkynen, 2011; Mäkynen et al., 2013). The spatial resolution of the MODIS ice thickness charts is $1 \mathrm{~km}$ and they show SIT values from 0 to $99 \mathrm{~cm}$. Only nighttime MODIS data was employed. Thus, the uncertainties related to the effects of solar shortwave radiation and surface albedo were excluded. For the cloud masking of the MODIS data, in addition to the different cloud tests (Frey et al., 2008), also manual methods were used in order to improve detection of thin clouds and ice fog. In the SIT chart calculation, an average snow thickness vs. ice thickness relationship was used (Mäkynen et al., 2013). This relationship is based on an empirical relationship between snow and ice thickness by Doronin (1971) and the Soviet Union's Sever expeditions data (NSIDC, 2004). The typical maximum reliable SIT ( $\max 50 \%$ uncertainty) for the MODIS data was estimated to be $35-50 \mathrm{~cm}$ under typical weather conditions (air temperature $<-20^{\circ} \mathrm{C}$, wind speed $5 \mathrm{~m} \mathrm{~s}^{-1}$ ). The accuracy is the best for the $15-30 \mathrm{~cm}$ thickness range, with an error of around $38 \%$. These figures are based on the Monte Carlo method using estimated or guessed standard deviations and covariances of the input variables to the SIT retrieval. No in situ data were available for the MODIS SIT accuracy estimation.
Since originally MODIS has a much higher spatial resolution than SMOS, the MODIS data were averaged to the SMOS resolution. Another smaller discrepancy between the two data sets is that, when calculating the SMOS SIT, the data of one day is averaged while the MODIS data stem from single overflights.

The SMOS and MODIS SIT retrievals for one single day, 4 December 2010, are shown in Fig. 7 (top left and top centre, respectively). The MODIS image shows incomplete coverage due to clouds. Some regions like northwest of Novaya Zemlya show a good agreement in shape and thickness distribution of the sea ice. In the image centre, east and south of the northeastern tip of Novaya Zemlya, SMOS retrieves higher SIT values than MODIS. Areas closer to the coast than $40 \mathrm{~km}$ are screened out because of potential land influence in the SMOS data. In Fig. 7 (top right) the averaged MODIS SIT values suitable for comparison with SMOS SIT are shown.

Similar analyses have been performed for all days with a sufficient number of coincident SMOS and MODIS thickness retrievals from 24 November to 14 April 2011 with 71 scenes in total (not shown here). Figure 7 (bottom) shows the combined scatter plot. As the data have been taken under a variety of different conditions, the scatter is considerably large with a correlation of $r=0.68$ and a RMSD with respect to the regression line of $11 \mathrm{~cm}$. The line has a slope of 1.75 , indicating that on average the SMOS retrieval gives $75 \%$ higher SIT than the MODIS retrieval. As a consequence, the two retrievals agree best at low thickness. The regression line has been determined by minimising the RMSD to the MODIS retrievals.

For the assessment of the comparison with MODIS derived SIT, it should be kept in mind that the MODIS SIT yields errors of mostly 40-50\% (Mäkynen et al., 2013). While the example shows good agreement of SIT from both sensors below $20 \mathrm{~cm}$ thickness which supports the conclusion of lower errors in this range (Table 2), we cannot attribute the statistic disagreement at higher thicknesses to any of the two sensors. In addition, the errors in the two retrievals stem from different sources. While the SMOS brightness temperatures are expected to have a higher random error due to lower radiometric accuracy and averaging over a large incident angle range as the atmosphere is close to transparent in the L band, MODIS ice surface temperature may be influenced by thin clouds and fog missed by the MODIS cloud mask.

\subsection{Using EM bird airborne measurements}

The AWI has developed an airborne instrument to measure SIT when attached to a plane or helicopter (Haas et al., 2009), called EM bird. The method employs the contrast in electrical conductivity between sea water and sea ice for determining the distance to the ice-water interface, and from a laser altimeter the distance to the ice top. The difference yields 

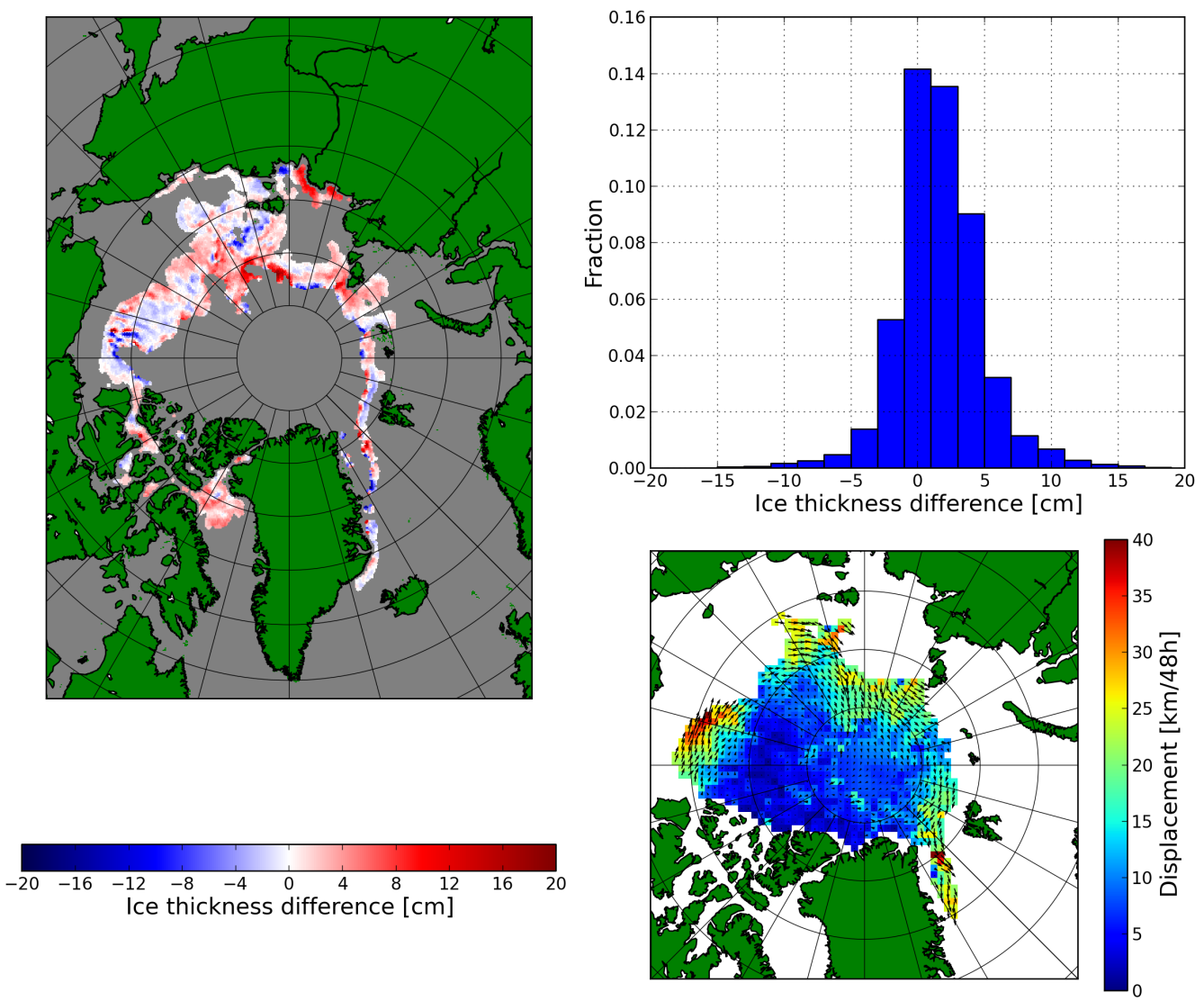

Fig. 10. Difference map of SMOS SIT retrieval from 20 to 21 October 2011 in the ice growth phase (left). Areas of open water and areas where the retrieval's $50+\mathrm{cm}$ flag is set are excluded. Histogram of day-to-day change from 20 to 21 October 2011 (top right). OSISAF sea ice displacement product from 19 to 21 October 2011 (bottom right).

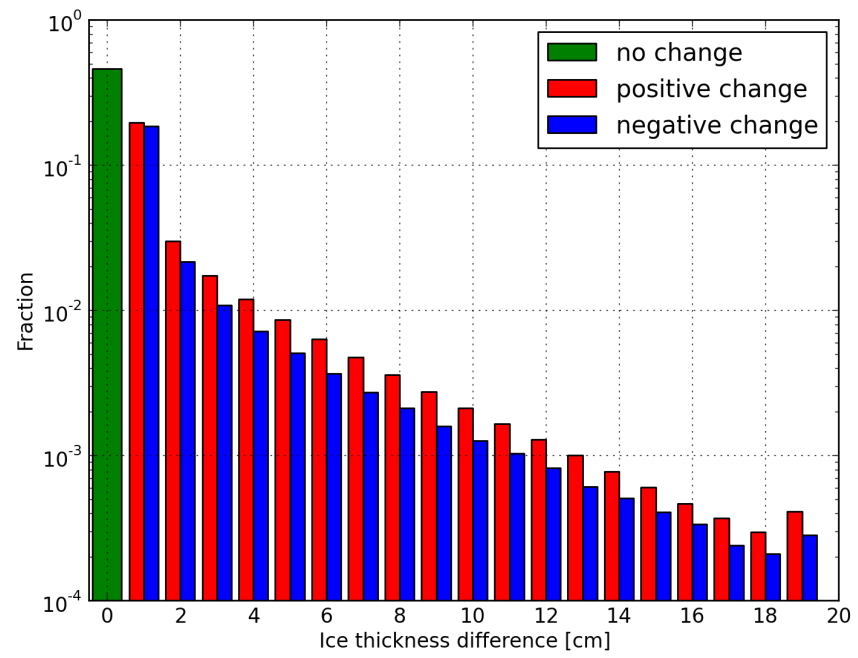

Fig. 11. Histogram of daily change of SIT from 1 October to 26 December 2010. the ice thickness (Haas et al., 2009). It takes a measurement every 3-4 m with typical footprint size of 40-50 m diameter.

The SITs are determined at an absolute error of less than $10 \mathrm{~cm}$ for a single measurement (Haas et al., 2009). For freshly frozen thin sea ice, the EM bird might underestimate the SIT since its conductivity is higher due to the higher salinity (Krumpen et al., 2012). In regions like the Laptev Sea known for high variations in salinity trough the year, the influence of the insufficiently known salinity has to be checked. An estimate of the mean and standard deviation of weekly sea surface salinity is given in Tian-Kunze et al. (2013). The error associated to the conductivity assumptions of the EMbird processing are estimated to be within the range of the instrument error because, during processing, manually identified regions of open waters are used to constantly calibrate the EM-signal. The uncertainty in the EM bird results of about $10 \mathrm{~cm}$ makes it suitable for validating SMOS SIT retrievals, which are expected to have a clearly higher uncertainty, especially in the upper thickness range. 
On 20 April 2012 EM bird measurements were taken during a helicopter flight in the Laptev Sea over freshly frozen thin sea ice with negligible snow cover, shown in Fig. 8 together with the SMOS retrieved SIT.

The considerable variability of the EM bird ice thicknesses within one single SMOS grid cell is shown in the histograms on the left. As the meteorological conditions of ice formation should have been quite homogeneous within the SMOS footprints during the short lifetime of this thin ice, the variability of ice thickness at this small horizontal scale should mainly be caused by mechanical redistribution of ice through the process of ridging, rafting, and shearing, as it has been documented for ice thicker than approximately $2 \mathrm{~m}$ by Wadhams $(1983,1992)$, finding exponential distributions. Here, the logarithmic representation of the histograms reveals similar exponential distributions also for sea ice in the thickness range from 0.5 to $1.5 \mathrm{~m}$. Close to the turning point of the helicopter (points 2, 3, 6, and 7) the SMOS retrievals are around $45 \mathrm{~cm}$ (purple), and those from the EM bird are mainly above $50 \mathrm{~cm}$ thickness but also contain a few thin values of around $10 \mathrm{~cm}$, possibly caused by leads much smaller than the SMOS footprint size (see black circle in Fig. 8 (right) for an example). Since the EM bird measurements and the corresponding averages are taken along a narrow line of its footprints of 40-50 m width, but the SMOS footprint covers a large area of about $50 \mathrm{~km}$ in diameter, we have to expect larger discrepancies in the SIT retrievals from the two instruments. The fraction of SMOS footprint area covered by EM bird measurements along one flight track is about $0.1 \%$ or less. The coloured vertical lines in the histograms in Fig. 8 correspond to the mean (purple) and median (cyan) of all EM bird measurements within the corresponding SMOS footprint. The yellow lines indicate the retrieved SIT by SMOS. In almost all cases the SMOS retrieval agrees better with the median because it is less influenced by the long tail of high thickness values in the distribution. The only case of larger disagreement is histogram 14, where the EM bird median thickness is $25 \mathrm{~cm}$ and the SMOS thickness exceeds its limit of $50 \mathrm{~cm}$. This is in agreement with the map in Fig. 8 (right) where the SMOS SIT mostly exceeds $50 \mathrm{~cm}$ within the size of a footprint (black circle) around point 14 . Apparently these thick ice regions are missed by the EM bird measurements (small gray dots) as can be seen in the histogram. This is an example for the more general case where parts of the SMOS footprint are covered by ice thicker than SMOS can retrieve. Therefore, this case is excluded from the comparison in Fig. 9. The histogram of point 3 near the turning point of the flight shows a pronounced bi-modal shape indicating at least two different regimes of ice thickness within this SMOS footprint. As the EM bird thicknesses in Fig. 8 are the best large-scale in situ observations of thin sea ice we currently have, we perform the comparison in the scatter plot of Fig. 9 in spite of the small number of data points from a quite limited region and season entering the comparison. The diagram shows a good agreement with correlation coefficient $r=0.73$ and RMSD of $5 \mathrm{~cm}$.

\subsection{Day-to-day differences - plausibility check}

The two preceding sections have shown the limitedness in space, time and sea ice thickness of validation data available to us. Therefore, as an additional, more global consistency check the SIT difference of two consecutive days, 20 and 21 October 2011, was investigated (Fig. 10, left). As the thermodynamic thickness growth within one day is limited, large changes are either due to drift or errors in the retrieval. In most regions of the map the change is a few centimetres. In the Beaufort Sea $\left(75^{\circ} \mathrm{N}, 140^{\circ} \mathrm{W}\right)$, narrow parallel bands of opposite sign in SIT difference indicate sea ice drift which is confirmed by the vectors (Fig. 10, bottom right) of the sea ice drift product from the OSI-SAF (Lavergne et al., 2010) running perpendicular to the bands of high sea ice thickness change. Other regions of high thickness change are found near the upper limit of the retrieved sea ice thicknesses where the retrieval noise is higher, extending e.g. east of northern Greenland, and north of Svalbard and Franz Josef Land. The strong increase in thickness in the Laptev Sea is in good agreement with CFDD based modelled growth of very thin ice at temperatures of around $-10^{\circ} \mathrm{C}$.

Figure 11 provides histograms of all positive (red) and negative (blue) day-to-day changes from October to December 2010. The plausible changes between $\pm 1 \mathrm{~cm}$ occur most frequently. This range covers about $90 \%$ of all pixels. Negative changes of $1 \mathrm{~cm}$ thickness are considered plausible here because of the uncertainty of the retrieval procedure. According to the overall sea ice increase in the freezing season, in all days the positive changes overbalance the negative ones. The average daily increase in SIT is $0.3 \mathrm{~cm}$ with a standard deviation of $3.3 \mathrm{~cm}$ reflecting the average ice thickness change throughout the Arctic. Higher changes in SIT than $\pm 8 \mathrm{~cm}$ are detected in less than $0.5 \%$ of the cases. Such strong ice thickness changes will not be generated thermodynamically but are drift or other disturbing influences, as, according to Eq. (2), an ice thickness growth from, e.g. 2 to $10 \mathrm{~cm}$ within one day requires an air temperature of $-30{ }^{\circ} \mathrm{C}$. In conclusion, the SMOS data generally provides a realistic scenario for a daily ice thickness development in the Arctic during the freeze-up period.

\section{Discussion and conclusions}

An empirical retrieval of SIT in the freeze-up period using $\mathrm{L}$ band $(1.4 \mathrm{GHz})$ brightness temperatures of sea ice acquired by SMOS has been developed. The retrieval is trained by a CFDD based model in the Kara and Barents seas during the freeze-up period and uses intensity (the average of horizontally and vertically polarised brightness temperatures) as well 
as the polarisation difference at incidence angles between 40 and $50^{\circ}$.

Table 2 concludes the calibration and validation errors from the various sources. The calibration data set reveals a strong increase of the retrieval error from $3 \mathrm{~cm}$ for thickness below $10-16 \mathrm{~cm}$ in the range from 40 to $50 \mathrm{~cm}$ thickness. The overall average error is $10 \mathrm{~cm}$. The two comparison data sets, based on MODIS and EM bird measurements, respectively, confirm the tendency of better retrievals for lower ice thickness. However, as both data sets are sparse, we only give overall retrieval errors. They are 11 and $5 \mathrm{~cm}$, respectively. Compared to the average error of the learning data set $(10 \mathrm{~cm})$ these values appear quite optimistic which may be explained by the small size, the homogeneity and the specific thickness distribution of the validation data sets. As the retrieval error increases with thickness, the actual error of any validation data set will depend on its thickness distribution, with higher errors for thicker ice. In Arctic-wide applications, we have to expect the average thickness towards the high end of the retrieval range of $0-50 \mathrm{~cm}$ as the ice growth rate decreases with thickness (Eq. 2). The most accurate validation data is the AWI EM bird sea ice thicknesses observations. Here, the correlation with the SMOS based thickness is 0.73 while the correlation between the example of MODIS and SMOS based retrievals is 0.68 , again supporting the suggested method.

It should be noted that the thickness range retrieved here is only found during the freeze-up season. During melt, the sea ice cover is too inhomogeneous for this method to be applied, with the mixture of wet sea ice, melt ponds and open water to be expected within one SMOS footprint. As a consequence, the method is applicable, as a rule of thumb, in the Arctic from October to April and in the Antarctic from March to October. Even during this time, melt or rain events may also lead to single misleading results. However, the comparison with the MODIS based thicknesses presented in the scatter plot of Fig. 7 covers the complete season from November 2010 to April 2011 in a statistically representative way.

As the validation studies indicate a good agreement between the two investigated data sets, further investigation to explain and understand this relationship using a microwave emission model is desirable. This will specifically aim to quantify the additional influence of temperature, salinity and wind speed on intensity and polarisation difference.

Sensitivity studies with a radiative bulk sea ice model show little increase of intensity with increasing temperature and salinity (Maaß, 2013). The polarisation difference also increases little with salinity, but more with temperature when it approaches melting. At higher ice thickness under freezing conditions (for which the algorithm is intended), we expect lower ice temperatures, where the temperature influence on the polarisation difference is again small.

Snow is nearly transparent at $\mathrm{L}$ band, but a noticeable effect is expected from the indirect influence of snow by thermal insulation, leading to higher ice temperatures, and thus to higher polarisation difference, increased brine volume, higher permittivity and thinner thickness retrievals (Fig. 6). We thus expect the strongest influences on the retrieval from temperature and snow cover and we suggest these should be investigated further. However, as the method presented here is completely empirical, the mentioned influences should automatically be included in a statistical way, e.g. a snow cover increasing statistically as the ice ages and becomes thicker. As the present study shows, even without taking these influences into account, the retrieval works within the indicated limits. Discrepancies can be expected if applied in regions with much snowfall, e.g. in the Pacific sector of the Southern Ocean where the algorithm has been applied successfully, too (not shown here). Another restriction of the algorithm is the assumption of $100 \%$ SIC. While attempts to include SIC as a second parameter into the retrieval have turned out to be very sensitive to noise of the input data (Sect. 3), restricting the retrieval to near $100 \%$ sea ice cover (obtained from other passive microwave sensors) could improve the accuracy of the retrieval. However, the focus of this study is a single-sensor retrieval.

Since SMOS brightness temperatures are quite sensitive to the incidence angle in the range of $40-50^{\circ}$ (Fig. 1), we are currently working on improving the retrieval by using the incidence angle as an explicit parameter.

The present retrieval and that suggested by Kaleschke et al. (2012) use different, independently taken data as they use disjoint incidence angle ranges $\left(0-40^{\circ}\right.$ vs. $\left.40-50^{\circ}\right)$. In future, both retrievals could be combined, e.g. by fitting an analytical curve to the observations of all incidence angles within one grid cell and then determining the ice thickness from the parameters of that curve.

In the training, only thermodynamic and no dynamic ice growth in the Kara Sea and Barents Sea is assumed. One possibility to exclude ice thickness changes by drift from a learning data set would be to use a fast ice region, e.g. in the Laptev Sea. However, using such a data set would risk leading one to a retrieval biased towards the characteristics of undeformed ice.

Another sensor observing sea ice thickness since 2012 is CryoSat2 (Laxon et al., 2013). While SMOS is sensitive to thin ice thickness only, the altimeter CryoSat2 has the highest uncertainty for thin sea ice and is more accurate for thicker sea ice of more than $1 \mathrm{~m}$. Comparing spatial distributions of ice thicknesses from both sensors can serve as another consistency check, and, if successful, a combined data product could cover a larger thickness range than each single one of the two sensors. However, such comparison and combination will have to be done on the base of monthly averages because a daily data product of CryoSat 2 sea ice thicknesses is currently not available. 
Acknowledgements. Financial support of the European Space Agency (ESA) project SMOSIce, contract no. 4000101476, the EU project Sea Ice Downstream services for Arctic and Antarctic Users and Stakeholders (SIDARUS), grant agreement 262922 and Federal Ministry of Education and Research/Bundesministerium für Bildung und Forschung (BMBF) MiKliP project Climate Model Validation by confronting globally Essential Climate Variables from models with observations (ClimVal) is gratefully acknowledged. The authors thank the National Centers for Environmental Prediction (NCEP) for data provision and the editor and reviewers for their helpful comments which greatly improved the quality.

Edited by: J. Stroeve

\section{References}

Bilello, M.: Formation, growth, and decay of sea-ice in the Canadian Arctic Archipelago, Arctic, 1961.

Brown, M., Torres, F., Corbella, I., and Colliander, A.: SMOS Calibration, IEEE Transactions on Geoscience and Remote Sensing, 46, 646-658, doi:10.1109/TGRS.2007.914810, 2008.

Camps, A., Gourrion, J., Tarongi, J. M., Gutierrez, A., Barbosa, J., and Castro, R.: RFI Analysis in SMOS Imagery, in: Geoscience and Remote Sensing Symposium (IGARSS proceedings 2010), 2007-2010, 2010.

Castro, R.: Analytical Pixel Footprint, Tech. rep., available at: http://www.smos.com.pt/downloads/release/documents/ SO-TN-DME-L1PP-0172-Analytical-Pixel-Footprint.pdf (last access: 17 March 2014), 2008.

Corbella, I., Duffo, N., Vall-1lossera, M., Camps, A., and Torres, F.: The visibility function in interferometric aperture synthesis radiometry, IEEE Trans. Geosci. Remote Sens. 42, 1677-1682, doi:10.1109/TGRS.2004.830641, 2004.

Doronin, Y. P.: Thermal Interaction of the Atmosphere and Hydrosphere in the Arctic, Isr. Program for Sci. Transl., Jerusalem, 1971.

Frey, R. a., Ackerman, S. A., Liu, Y., Strabala, K. I., Zhang, H., Key, J. R., and Wang, X.: Cloud Detection with MODIS. Part I: Improvements in the MODIS Cloud Mask for Collection 5, J. Atmos. Ocean. Technol., 25, 1057-1072, doi:10.1175/2008JTECHA1052.1, 2008.

Fuhrhop, R., Grenfell, T., and Heygster, G.: A combined radiative transfer model for sea ice, open ocean, and atmosphere, Radio Science, 33, 303-316, doi:10.1029/97RS03020, 1998.

Haas, C., Lobach, J., Hendricks, S., Rabenstein, L., and Pfaffling, A.: Helicopter-borne measurements of sea ice thickness, using a small and lightweight, digital EM system, J. Appl. Geophys., 67, 234-241, doi:10.1016/j.jappgeo.2008.05.005, 2009.

Heygster, G., Huntemann, M., and Wang, H.: Algorithm Theoretical Basis Document (ATBD) for the University of Bremen Polarization-based SMOS sea ice thickness retrieval algorithm (Algorithm II), Tech. Rep. Algorithm II, Institute of Environmental Physics, Bremen, Germany, 2012.

Kaleschke, L., Maaß, N., Haas, C., Hendricks, S., Heygster, G., and Tonboe, R. T.: A sea-ice thickness retrieval model for $1.4 \mathrm{GHz}$ radiometry and application to airborne measurements over low salinity sea-ice, The Cryosphere, 4, 583-592, doi:10.5194/tc-4583-2010, 2010.
Kaleschke, L., Tian-Kunze, X., Maaß, N., Mäkynen, M., and Drusch, M.: Sea ice thickness retrieval from SMOS brightness temperatures during the Arctic freeze-up period, Geophys. Res. Lett., 39, L05501, doi:10.1029/2012GL050916, 2012.

Källen, E.: HIRLAM Documentation Manual, System 2.5, Tech. rep., Swed. Meteorol. and Hydrol. Inst, Norrköping, Sweden, 1996.

Kalnay, E., Kanamitsu, M., Kistler, R., Collins, W., Deaven, D., Gandin, L., Iredell, M., Saha, S., White, G., Woollen, J., Zhu, Y., Leetmaa, A., Reynolds, R., Chelliah, M., Ebisuzaki, W., Higgins, W., Janowiak, J., Mo, K. C., Ropelewski, C., Wang, J., Jenne, R., and Joseph, D.: The NCEP/NCAR 40-Year Reanalysis Project, Bull. Am. Meteorol. Soc., 77, 437-471, doi:10.1175/15200477(1996)077<0437:TNYRP>2.0.CO;2, 1996.

Kern, S., Spreen, G., Kaleschke, L., Rosa, S. D. E. L. A., and Heygster, G.: Polynya Signature Simulation Method polynya area in comparison to AMSR-E $89 \mathrm{GHz}$ sea-ice concentrations in the Ross Sea and off lie Coast, Antarctica, for 2002-05 : first results the Ade, 409-418, doi:10.3189/172756407782871585, 2007.

Kerr, Y., Waldteufel, P., Wigneron, J.-P., Martinuzzi, J., Font, J., and Berger, M.: Soil moisture retrieval from space: the Soil Moisture and Ocean Salinity (SMOS) mission, IEEE Trans. Geosci. Remote Sens., 39, 1729-1735, doi:10.1109/36.942551, 2001.

Krumpen, T., Hedricks, S., and Haas, C.: Data report on EM-Bird ice thickness measurements for SMOSIce validation obtained during Transdrift XX, ARK XXVII/3 and SafeWin 2011 campaigns, Tech. rep., Alfred Wegener Institute for Polar and Marine Research, Bremerhaven, Germany, 2012.

Kwok, R., Comiso, J. C., Martin, S., and Drucker, R.: Ross Sea polynyas: Response of ice concentration retrievals to large areas of thin ice, J. Geophys. Res., 112, C12012, doi:10.1029/2006JC003967, 2007.

Launiainen, J. and Cheng, B.: Modelling of ice thermodynamics in natural water bodies, Cold Reg. Sci. Technol., 27, 153-178, 1998.

Lavergne, T., Eastwood, S., Teffah, Z., Schyberg, H., and Breivik, L.-a.: Sea ice motion from low-resolution satellite sensors: An alternative method and its validation in the Arctic, J. Geophys. Res., 115, C10032, doi:10.1029/2009JC005958, 2010.

Laxon, S. W., Giles, K. A., Ridout, A. L., Wingham, D. J., Willatt, R., Cullen, R., Kwok, R., Schweiger, A., Zhang, J., Haas, C., Hendricks, S., Krishfield, R., Kurtz, N., Farrell, S., and Davidson, M.: CryoSat-2 estimates of Arctic sea ice thickness and volume, Geophys. Res. Lett., 40, 732-737, doi:10.1002/grl.50193, 2013.

Maaß, N.: Remote sensing of sea ice thickness using SMOS data, Ph.D. thesis, 2013.

Mäkynen, M.: STSE-SMOS Sea Ice Retrieval Study SMOSIce WP 3 Assembly of the SMOSIce Data Base SMOSIce-DAT user manual for the validation data Deliverable D-6b Draft EUROPEAN SPACE AGENCY STUDY CONTRACT REPORT Under ESTEC Contract No. 4000101476/10/NL/CT, Tech. rep., 2011.

Mäkynen, M., Cheng, B., and Simila, M.: On the accuracy of thin-ice thickness retrieval using MODIS thermal imagery over Arctic first-year ice, Ann. Glaciol., 54, 87-96, doi:10.3189/2013AoG62A166, 2013.

Mecklenburg, S., Drusch, M., Kerr, Y. H., Font, J., MartinNeira, M., Delwart, S., Buenadicha, G., Reul, N., DaganzoEusebio, E., Oliva, R., and Crapolicchio, R.: ESA's Soil Moisture and Ocean Salinity Mission: Mission Performance and Op- 
erations, IEEE Trans. Geosci. Remote Sens., 50, 1354-1366, doi:10.1109/TGRS.2012.2187666, 2012.

NSIDC: Morphometric characteristics of ice and snow in the Arctic Basin: aircraft landing observations from the Former Soviet Union, 1928-1989, Compiled by I. P. Romanov, Boulder, CO: National Snow and Ice Data Center, Digital medi., 2004.

Oliva, R., Daganzo, E., Kerr, Y. H., Mecklenburg, S., Nieto, S., Richaume, P., and Gruhier, C.: SMOS Radio Frequency Interference Scenario: Status and Actions Taken to Improve the RFI Environment in the 1400-1427-MHz Passive Band, IEEE Trans. Geosci. Remote Sens., 50, 1427-1439, doi:10.1109/TGRS.2012.2182775, 2012.

Sahr, K., White, D., and Kimerling, A. J.: Geodesic Discrete Global Grid Systems, Cartography and Geographic Information Science, 30, 121-134, doi:10.1559/152304003100011090, 2003.

Sakov, P., Counillon, F., Bertino, L., Lisæter, K. A., Oke, P. R., and Korablev, A.: TOPAZ4: an ocean-sea ice data assimilation system for the North Atlantic and Arctic, Ocean Sci., 8, 633-656, doi:10.5194/os-8-633-2012, 2012.

Spreen, G., Kaleschke, L., and Heygster, G.: Sea ice remote sensing using AMSR-E 89-GHz channels, J. Geophys. Res., 113, C02S03, doi:10.1029/2005JC003384, 2008.

Tian-Kunze, X., Kaleschke, L., Maßß, N., Mäkynen, M., Serra, N., Drusch, M., and Krumpen, T.: SMOS derived sea ice thickness: algorithm baseline, product specifications and initial verification, The Cryosphere Discuss., 7, 5735-5792, doi:10.5194/tcd7-5735-2013, 2013.
Tonboe, R. T., Dybkjaer, G., and Høyer, J. L.: Simulations of the snow covered sea ice surface temperature and microwave effective temperature, Tellus A, 63, 1028-1037, doi:10.1111/j.16000870.2011.00530.x

2011.

Unden, P., Rontu, L., Järvinen, H., and Lynch, P.: HIRLAM5 scientific documentation, available at: http://citeseerx.ist psu.edu/viewdoc/summary?doi=10.1.1.6.3794 (last access: 17 March 2014), 2002.

Wadhams, P.: Sea ice thickness distribution in Fram Strait, Nature, 305, 108-111, doi:10.1038/305108a0, 1983.

Wadhams, P.: Sea ice thickness distribution in the Greenland Sea and Eurasian Basin, May 1987, J. Geophys. Res., 97, 5331, doi:10.1029/91JC03137, 1992.

Weeks, W.: On Sea Ice, University of Alaska Press, 2010.

Yu, Y. and Rothrock, D. A.: Thin ice thickness from satellite thermal imagery, J. Geophysi. Res., 101, 25753-25766, doi:10.1029/96JC02242, 1996.

Zine, S., Boutin, J., Font, J., Reul, N., Waldteufel, P., Gabarro, C., Tenerelli, J., Petitcolin, F., Vergely, J.-L., Talone, M., and Delwart, S.: Overview of the SMOS Sea Surface Salinity Prototype Processor, IEEE Trans. Geosci. Remote Sens., 46, 621-645, doi:10.1109/TGRS.2008.915543, 2008. 